\title{
Corneal Hydrops Secondary to Intrastromal Corneal Ring Intrusion into the Anterior Chamber 7 Years after Implantation: A Case Report
}

\author{
Majid Moshirfar · Andrew E. Bean · Jordan D. Desautels · Orry C. Birdsong
}

Received: July 15, 2017 / Published online: August 28, 2017

(C) The Author(s) 2017. This article is an open access publication

\begin{abstract}
Introduction: This report describes the first known case of late-onset intrusion of an intrastromal ring segment into the anterior chamber due to posterior migration of a ring segment. To our knowledge, intrastromal ring segment penetration has only been shown to occur in the intraoperative or immediate postoperative period. We postulate that the perforation in this case is due to progressive thinning of the cornea, possibly in combination with habitual eye rubbing.

Case Report: A 44-year-old man presented with acute corneal hydrops related to penetration of Descemet's membrane and endothelium by an
\end{abstract}

Enhanced content To view enhanced content for this article go to http://www.medengine.com/Redeem/ DFEBF0603B8BF7CC.

M. Moshirfar $(\bowtie) \cdot$ J. D. Desautels · O. C. Birdsong HDR Research Center, Hoopes Vision, Salt Lake City, UT, USA

e-mail: cornea2020@me.com

M. Moshirfar

Department of Ophthalmology and Visual Sciences, John A. Moran Eye Center, University of Utah

School of Medicine, Salt Lake City, UT, USA

A. E. Bean

McGovern Medical School, Houston, TX, USA

J. D. Desautels

Warren Alpert Medical School of Brown University, Providence, USA intrastromal ring segment implanted 7 years prior. Removal of the ring segment resulted in an anterior chamber fistula that directed fluid through the ring segment tunnel to the ocular surface. Leakage of aqueous humor was successfully controlled, and corneal edema gradually resolved.

Conclusion: This case indicates the need for long term monitoring of ring segment proximity to the posterior corneal surface, especially in patients with ectatic ocular conditions and/or habitual eye rubbing behavior.

Keywords: Corneal edema; Corneal hydrops; Corneal thinning; Descemet's rupture; Ectasia; INTACS; Intrastromal corneal ring; Keratoconus; LASIK

\section{INTRODUCTION}

INTACS intrastromal ring segment implantation was first developed to improve mild myopia. In current practice, the procedure is more commonly used to improve irregular corneal astigmatism in patients with keratoconus or post-LASIK kerectasia. INTACS implantation is considered a safe and effective treatment modality for progressive keratoconus [1]. However, the fragile nature of the ectatic cornea, alongside a demonstrated potential for INTACS migration within the stroma, presents a risk of anterior and posterior corneal surface 

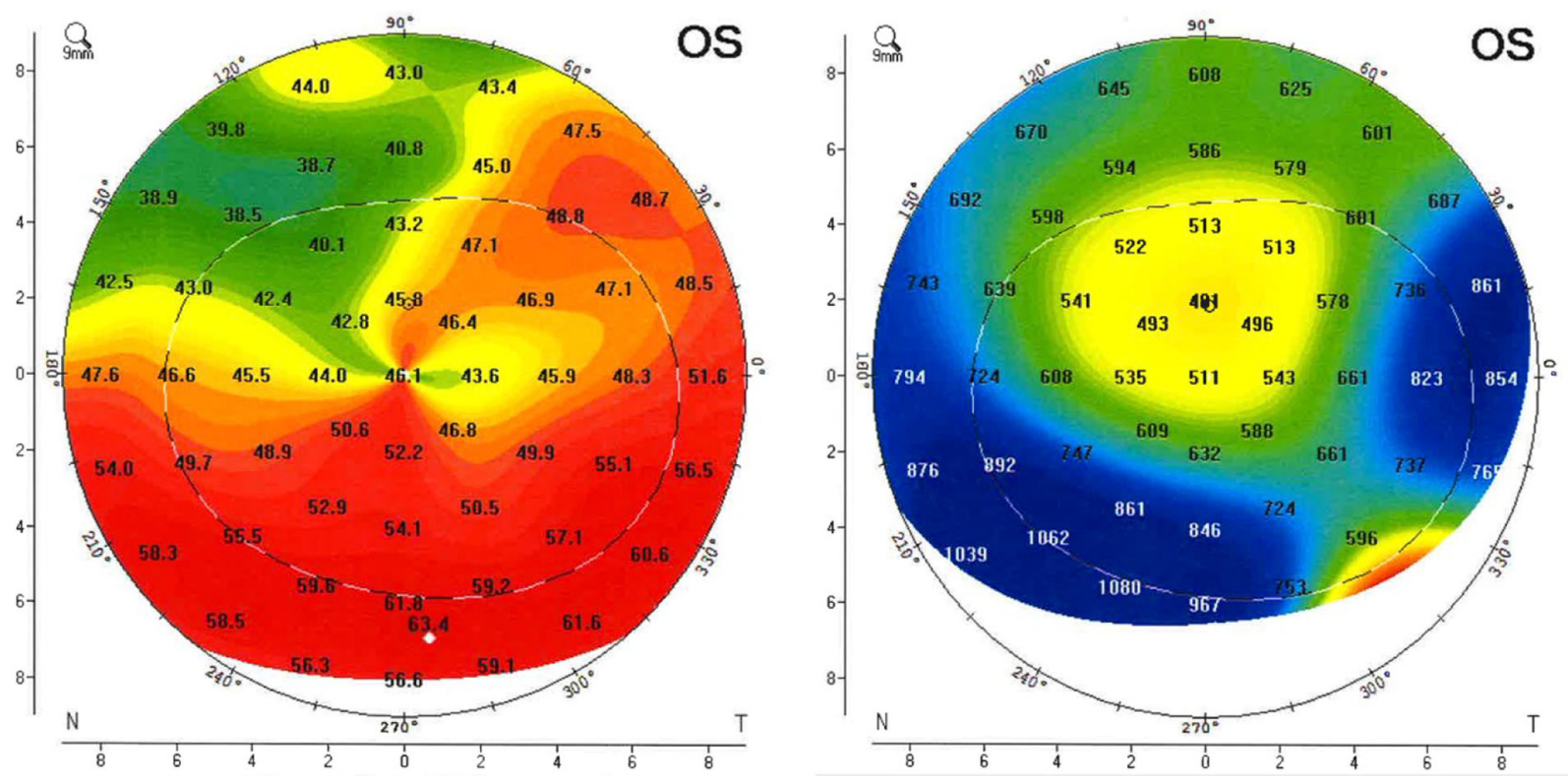

Fig. 1 Inferior corneal steepening (left) and pachymetry showing corneal thickening (right) at the time of presentation

perforation. Of particular concern are the risks of posterior corneal damage and loss of fluid equilibrium that may necessitate penetrating keratoplasty (PKP). Such occurrences are exceedingly rare, and thus far have only been reported in the intraoperative or immediate postoperative period. In this report, we describe the first known case of late-onset INTACS segment intrusion into the anterior chamber causing corneal hydrops 7 years after implantation.

\section{CASE REPORT}

A 44-year-old man was referred to our clinic following sudden onset irritation, blurry vision, and loosening of the single, inferiorly placed INTACS device in his left eye. His past ocular history is significant for LASIK surgery in 1996 and INTACS implantation in 2009 for LASIK-induced ectasia. At the time of presentation, his best corrected visual acuity (BCVA) was 20/500 in the left eye and 20/25 in the right eye. Slit-lamp examination revealed intrusion of the INTACS corneal ring segment into the anterior chamber that resulted in pronounced corneal edema, stromal opacification, and aqueous accumulation in the INTACS tunnel. These clinical signs were confirmed by elevated pachymetry $(1062 \mu \mathrm{m})$ and significant inferior topographic steepening $\left(K_{\max }=63.4 D\right)$ (Fig. 1$)$. Anterior segment optical coherence tomography (OCT) indicated a rupture through Descemet's membrane that compromised the endothelium with epithelial microcystic edema overlying the arc of the ring segment (Figs. 2, 3).

Progressive corneal thinning was determined to be the precipitating cause exacerbated by mechanical tissue trauma related to habitual eye rubbing. Corneal edema was refractory to 3 weeks of treatment with $5 \%$ sodium chloride solution bid and to combination brimonidine/timolol bid. BCVA further worsened to counting fingers at six feet at 1 week from presentation. The persistent edema was determined to be due to perforation of the endothelium by the intrastromal ring segment. We elected to explant the INTACS segment through a $1.1 \mathrm{~mm}$ incision placed over the original implantation incision site with a Sinskey hook. Successful liberation of the INTACS device resulted in an egress of fluid from the anterior chamber onto the ocular surface. The anterior chamber 

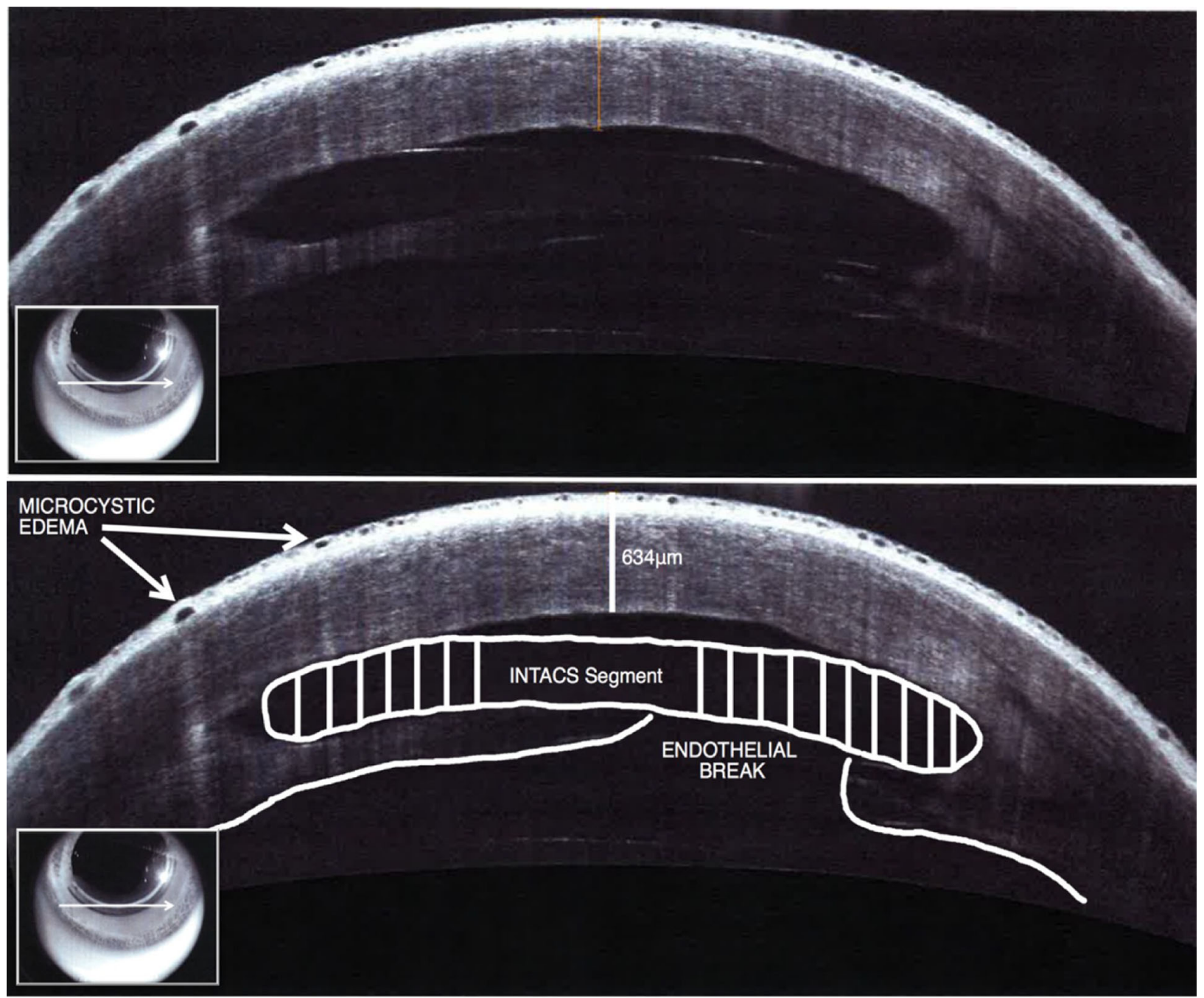

Fig. 2 Transverse anterior segment OCT image taken at the time of presentation (plane denoted by white arrow in frontal view). Fluid accumulation is clearly visible in the

became mildly shallow, but maintained fluid. This supported our original hypothesis of the presence of a fistula caused by acute perforation leading to the development of hydrops. A single suture was placed over the incision, and a bandage contact lens was applied under a pressure patch. At the 3-week post-operative visit, BCVA improved to $20 / 60$ in the treatment eye, with significant decrease in corneal edema. Maximum thickness was reduced on pachymetry from 1062 to $814 \mu \mathrm{m}$, but topography indicated persistent inferior steepening above the point of perforation $\left(K_{\max }=63.1\right.$ D) (Fig. 4). Anterior stromal tunnel surrounding the INTACS ring segment. Microcystic edema is present in the epithelium overlying the INTACS ring segment

segment OCT showed full resolution of epithelial microcystic edema (Fig. 5).

The patient involved was provided a written informed consent in accordance with the tenets of the Declaration of Helsinki to having their data used for research purposes.

\section{DISCUSSION}

Acute corneal hydrops describes stromal edema secondary to disruption of Descemet's membrane and endothelium [2]. Although the 


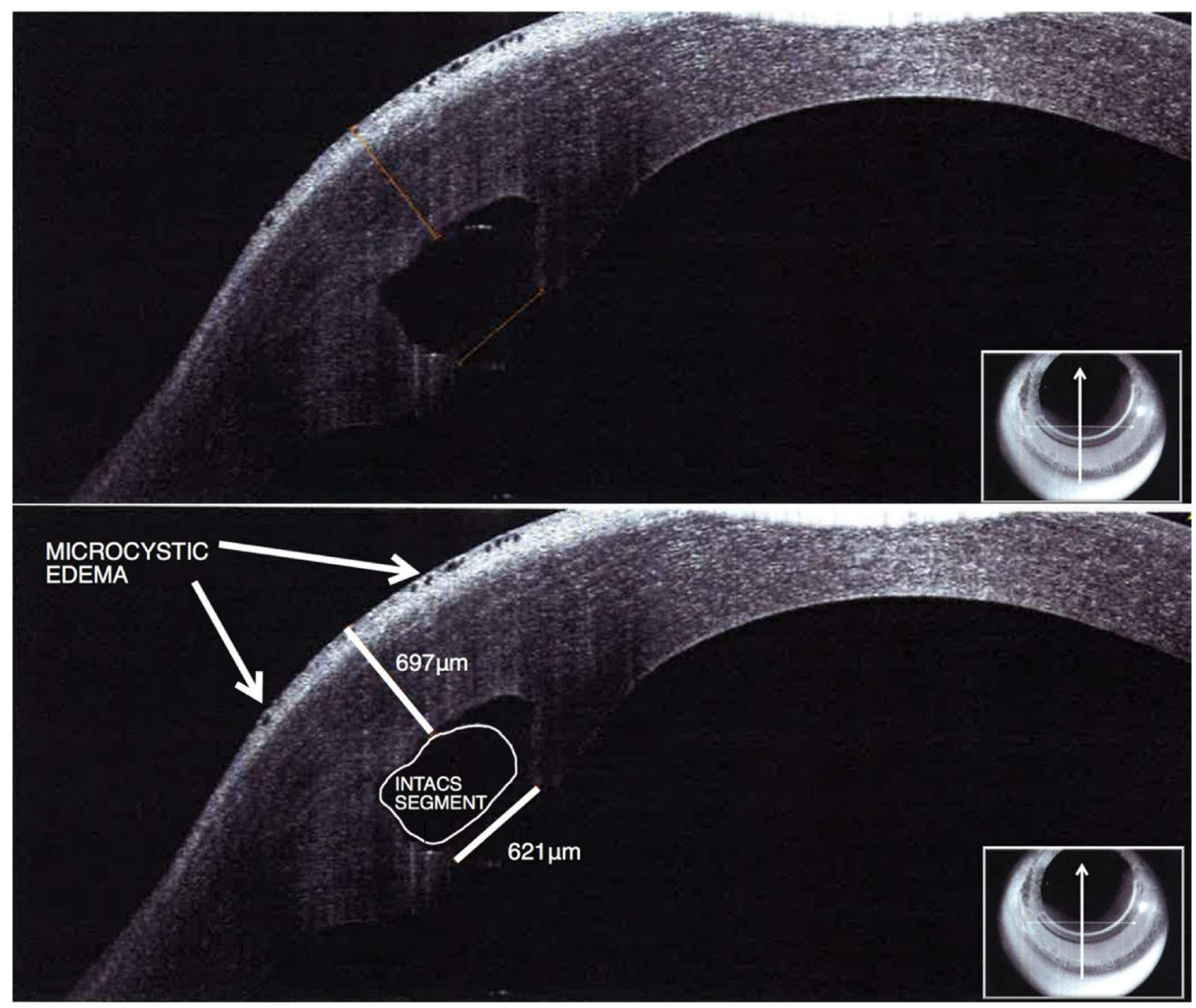

Fig. 3 Sagittal anterior segment OCT image taken at the time of presentation (plane denoted by white arrow in frontal view). Fluid accumulation is clearly visible in the

exact etiology of corneal hydrops is unclear, it is often associated with progressive ectatic disease, severe allergic eye disease, and habitual eye rubbing [2]. Rare cases can cause perforation and fistula formation [3]. In keratoconus patients, the onset of hydrops is generally spontaneous and proportional to the degree of corneal steepening [2]. As such, controlling or arresting the progression of ectasia with modalities such as collagen cross-linking (CXL), INTACS implantation, or newer allogenic intrastromal ring segments stromal tunnel surrounding the INTACS ring segment. Microcystic edema is present in the epithelium overlying the INTACS ring segment

such as CAIRS is likely to reduce the probability of acute hydrops.

However, INTACS implantation may itself prompt corneal hydrops in rare instances. Güell et al. report an experience with acute corneal hydrops related to an intraoperative break in Descemet's membrane while positioning an INTACS device in a keratoconic patient [4]. Corneal edema within 1 week of INTACS implantation has been reported and hypothesized to be related to the induction of endothelial dysfunction by the femtosecond 

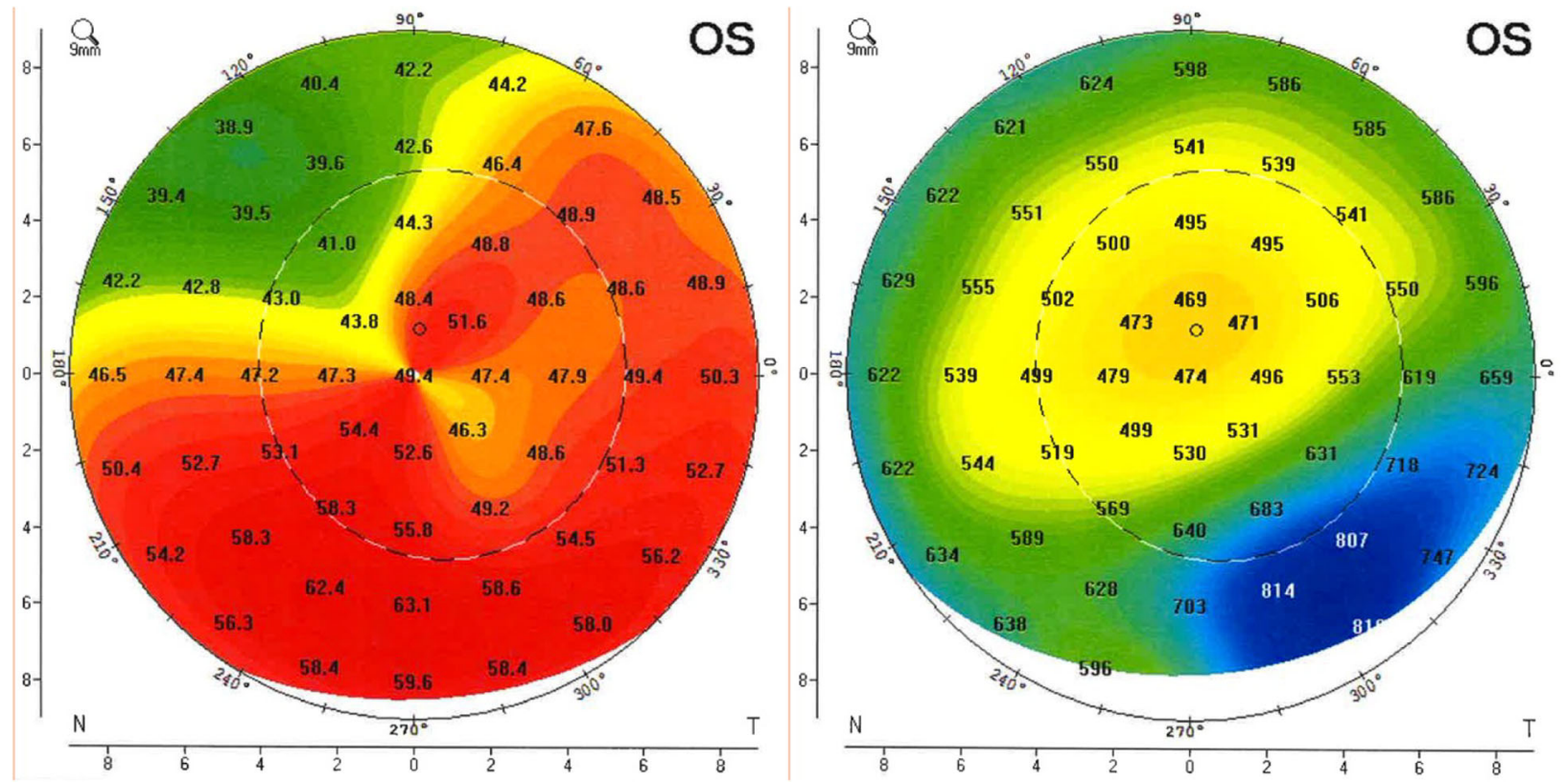

Fig. 4 Persistent inferior corneal steepening (left) and pachymetry showing reduced corneal thickening (right) after INTACS segment explant

laser used to create the INTACS stromal tunnel $[5,6]$. Antonios et al. report the only instance of significantly delayed corneal hydrops or edema with the concurrent presence of an INTACS device was in a patient with severe recurring allergic keratoconjunctivitis and keratoconus who underwent CXL and INTACS implantation 3 years prior [7]. There was no evidence of INTACS migration or corneal perforation, and the presence of the INTACS ring appears coincidental rather than causal. Our observed case of corneal hydrops and edema 7 years post-implantation has a clear causal link to the INTACS device due to a perforation in Descemet's membrane and endothelium.

Multiple instances of INTACS penetration into the anterior chamber during or shortly after implantation have also appeared in the literature [8-10]. Similar to the cases involving corneal edema, these instances are hypothesized to be due to an intraoperative insult of Descemet's membrane and underlying endothelium. This case is distinct because the penetration seems to be due to posterior corneal thinning and habitual eye rubbing. Moreover, although superficial migration and ring segment extrusion are well established, but rare complications of INTACS, the apparent posterior migration and intrusion into the anterior chamber seen in this patient has not been reported [11].

In order to avoid complications associated with shallow segment implantation, aiming for an implantation depth of $70 \%$ total corneal thickness is common practice $[12,13]$. Using three points above and below the implantation site, we calculated the average depth of our patient's INTACS segment to be $75.08 \%$ total corneal thickness [13]. It is unclear if this depth was part of the surgical plan or if it was due to posterior migration of the implant. While deep implantation helps to prevent ring segment extrusion and epithelial breakdown, posterior migration of the intrastromal ring segment could result in Descemet's rupture, endothelial compromise, and fistula formation as seen in our case. This is more likely in patients with ectatic conditions where corneal thinning can occur. Additionally, continuous mechanical push from habitual eye rubbing could also have contributed to posterior ring segment 


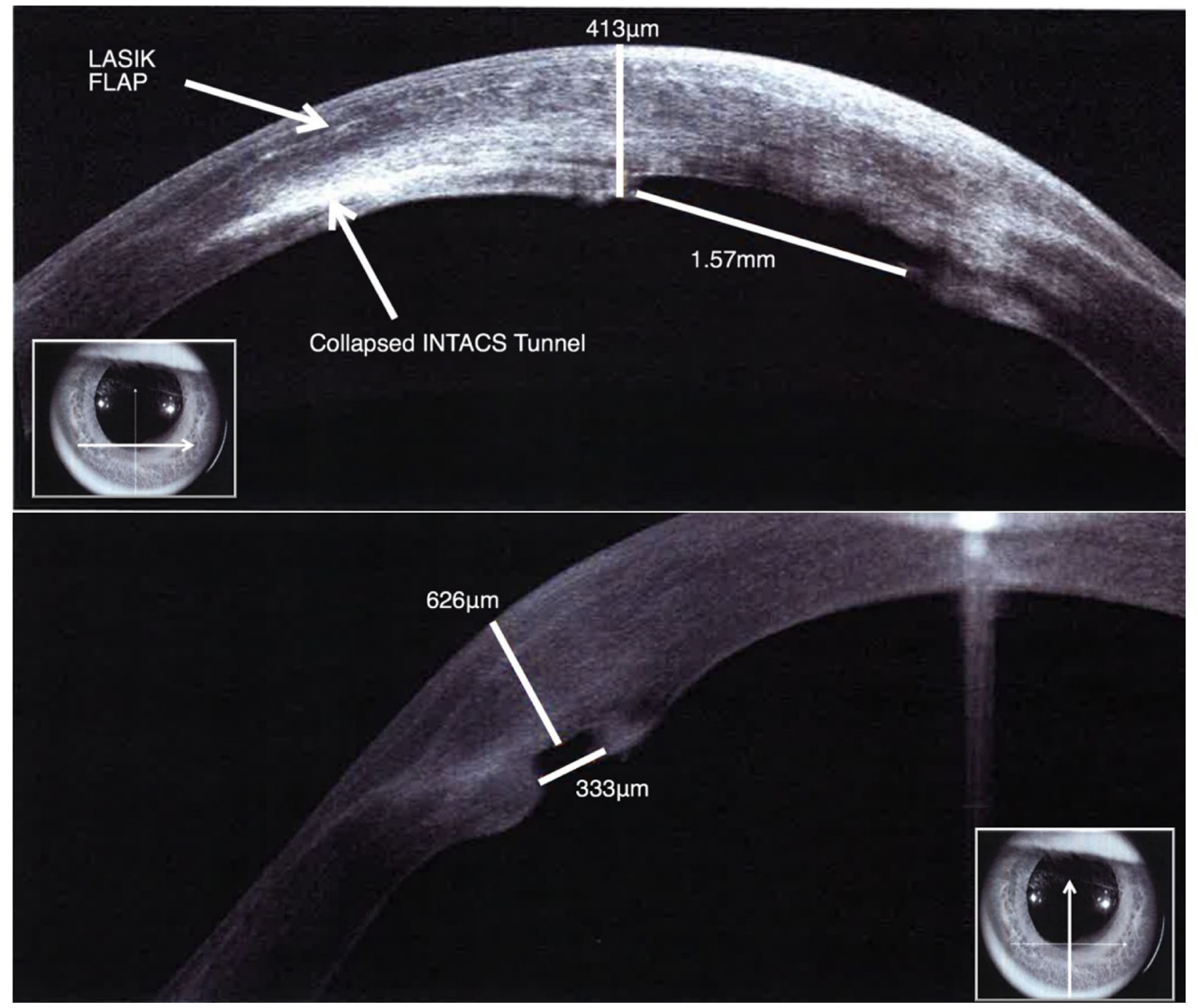

Fig. 5 Transverse (above) and sagittal (below) anterior segment OCT images taken 6 weeks after removal of the INTACS ring segment. Note significant reduction in

migration, especially since the segment appeared non-planar to the endothelial surface.

\section{CONCLUSION}

This case of intrastromal ring intrusion into the anterior chamber 7 years post-implantation indicates the importance of longitudinal follow up of INTACS patients to monitor the change in proximity of the intrastromal ring to the posterior cornea. Treatment of stromal edema and resolution of epithelial microcystic edema. A subtle endothelial break can be appreciated

implant-associated corneal hydrops should involve timely removal of the implant. Subsequent migration of endothelial cells to damaged areas could allow for the restoration of pump function and result in improved visual outcomes.

\section{ACKNOWLEDGEMENTS}

This study was funded by an unrestricted Grant from Research to Prevent Blindness. No support 
was received for the publication of this article. All named authors meet the International Committee of Medical Journal Editors (ICMJE) criteria for authorship for this manuscript, take responsibility for the integrity of the work as a whole, and have given final approval to the version to be published. Editorial assistance in preparation of this manuscript was provided by Mitchell Tingey of Brigham Young University.

Disclosures. Majid Moshirfar, Andrew E. Bean, Jordan D. Desautels and Orry C. Birdsong have nothing to disclose.

Compliance with Ethics Guidelines. The patient involved was provided a written informed consent in accordance with the tenets of the Declaration of Helsinki to having their data used for research purposes.

Data Availability. All data generated or analyzed during this study are included in the tables provided in this published article.

Open Access. This article is distributed under the terms of the Creative Commons Attribution-NonCommercial 4.0 International License (http://creativecommons.org/licenses/ by-nc/4.0/), which permits any noncommercial use, distribution, and reproduction in any medium, provided you give appropriate credit to the original author(s) and the source, provide a link to the Creative Commons license, and indicate if changes were made.

\section{REFERENCES}

1. Shetty R, Kurian M, Anand D, Mhaske P, Narayana $\mathrm{KM}$, Shetty BK. Intacs in advanced keratoconus. Cornea. 2008;27(9):1022-9.

2. Tuft SJ, Gregory WM, Buckley RJ. Acute corneal hydrops in keratoconus. Ophthalmology. 1994;101(10):1738-44.

3. Mostafavi D, Chu DS. Two cases of keratoconus associated with spontaneous corneal perforation. Cornea. 2010;29(7):825-7.
4. Güell JL, Verdaguer P, Elies D, Gris O, Manero F. Acute corneal hydrops after intrastromal corneal ring segment implantation for keratoconus. J Cataract Refract Surg. 2012;38(12):2192-5.

5. Deobhakta AA, Kymionis GD, Ide T, Yoo SH. Corneal edema after Intacs implantation with the femtosecond laser. J Cataract Refract Surg. 2008;34(1):174.

6. Ghajarnia M, Moshirfar M, Mifflin MD. Descemet detachment after femtosecond-laser-assisted placement of intrastromal ring segments in pellucid marginal degeneration. J Cataract Refract Surg. 2008;34(12):2174-6.

7. Antonios R, Dirani A, Fadlallah A, Chelala E, Hamadeh A, Jarade E. Acute corneal hydrops 3 years after intra-corneal ring segments and corneal collagen cross-linking. Middle East Afr J Ophthalmol. 2016;23(1):156-9.

8. Al-Amry M, Alkatan HM. Histopathologic findings in two cases with history of intrastromal corneal ring segments insertion. Middle East Afr J Ophthalmol. 2011;18(4):317-9.

9. Kanellopoulos AJ, Pe LH, Perry HD, Donnenfeld ED. Modified intracorneal ring segment implantations (INTACS) for the management of moderate to advanced keratoconus: efficacy and complications. Cornea. 2006;25(1):29-33.

10. Park S, Ramamurthi S, Ramaesh K. Late dislocation of intrastromal corneal ring segment into the anterior chamber. J Cataract Refract Surg. 2010;36(11):2003-5.

11. Coskunseven E, Kymionis GD, Tsiklis NS, Atun S, Arslan E, Siganos CS, et al. Complications of intrastromal corneal ring segment implantation using a femtosecond laser for channel creation: a survey of 850 eyes with keratoconus. Acta Ophthalmol. 2011;89(1):54-7.

12. Barbara A. Textbook on keratoconus: new insights. Puducherry: Jaypee Brothers, Medical Publishers Pvt. Limited; 2011.

13. Barbara R, Barbara A, Naftali M. Depth evaluation of intended vs actual intacs intrastromal ring segments using optical coherence tomography. Eye. 2016;30(1):102-10. 